\title{
Review on graphite foam as thermal material for heat exchangers
}

\author{
Wamei Lin, Jinliang Yuan, Bengt Sundén* \\ Department of Energy Sciences, Lund University, P.O.Box 118, SE-22100, Lund, Sweden \\ * Corresponding author. Tel: +46 46 2228605, Fax: +46 46 2224717, E-mail: bengt.sunden@energy.lth.se
}

\begin{abstract}
Due to the increased power consumptions in equipment, the demand of effective cooling methods becomes crucial. Because of the small scale spherical pores, graphite foam has huge specific surface area. Furthermore, the thermal conductivity of graphite foam is four times that of copper. The density of graphite foam is only $20 \%$ of that of aluminum. Thus, the graphite foam is considered as a novel highly - conductive porous material for high power equipment cooling applications. However, in the commercial market, aluminum and copper are still the preferred materials for thermal management nowadays. In order to promote the graphite foam as a thermal material for heat exchangers, an overall understanding of the graphite foam is needed. This paper describes the structure of the graphite foam. Based on the special structure, the thermal properties and the flowing characteristics of graphite foam are outlined and discussed. Furthermore, the application of graphite foam as a thermal material for heat exchangers is highlighted for electronic packages and vehicle cooling systems. The physical problems and other aspects, which might block the development of graphite foam heat exchangers, are pointed out. Finally, several useful conclusions and suggestions are given to promote the development of graphite foam heat exchangers.
\end{abstract}

Keywords: Graphite foam, heat exchanger, thermal management

\section{Introduction}

Nowadays the power of equipment is increased. For instance, the power of computer chips is increased, and the power of vehicle engines is also increased. This increased power leads to a requirement of an effective cooling method. Currently the thermal management has focused on aluminum and copper heat exchangers, because of high thermal conductivity (180 W/(m.K) for aluminum 6061 and $400 \mathrm{~W} /(\mathrm{m} . \mathrm{K})$ for copper). However, when the density is considered, the specific thermal conductivity of aluminum or copper (thermal conductivity divided by specific gravity) is only 54 and $45 \mathrm{~W} /(\mathrm{m} . \mathrm{K})$, respectively. Thus, when the weight is a significant factor, it is necessary to introduce a thermal material with low density, high thermal conductivity and large specific surface area.

An efficient thermal management method is the utilization of microcellular foam materials such as metal or graphite foams, based on the enhancement of heat transfer by huge fluidsolid contact surface area and the fluid mixing. An example of graphite foam application was developed at Oak Ridge National Laboratory (ORNL) in 1997. Klett et al. [1] found that the thermal conductivity of the solid component of graphite was as high as $1700 \mathrm{~W} /(\mathrm{m} . \mathrm{K})$, which was around four times that of copper. The effective thermal conductivity of graphite foam was more than $150 \mathrm{~W} /(\mathrm{m} . \mathrm{K})$, which was higher than the value of aluminum foam (2 - 26 $\mathrm{W} /(\mathrm{m} . \mathrm{K}))$. On the other hand, the density of graphite foam was $0.2-0.6 \mathrm{~g} / \mathrm{cm}^{3}$, which was only $1 / 5$ of that of aluminum. The specific surface area was between 5000 and $50000 \mathrm{~m}^{2} / \mathrm{m}^{3}$.

Because of the high thermal conductivity, low density and large specific surface area, the graphite foam is recognized as an appropriate material for the thermal management. It is primarily focused on the electronic power heat sinks. A large number of studies have been carried out to analyze graphite foam heat exchangers. However, in the commercial market of heat exchangers, aluminum and copper are still the preferred thermal material. Thus, there are several problems blocking the development of graphite foam heat exchangers. Otherwise the graphite foam heat exchangers would be easily found in the market. 
In order to promote the development of graphite foam as a thermal material for heat exchangers, this paper will present an overall view or conception about graphite foam heat exchangers. Firstly, the structure of graphite foam is introduced in Section 2. Based on the structure of graphite foam, the thermal properties and flow characteristics of graphite foam are explained in Section 2 as well. After that, the application of graphite foam heat exchangers is outlined in Section 3. In Section 4, potential problems blocking the development of graphite foam heat exchangers are pointed out. Based on the review and analysis, several useful conclusions and suggestions are highlighted in Section 5.

\section{Structures and properties of graphite foam}

\subsection{Structures}

Carbon foams were first developed in the late 1960s as reticulated vitreous (glassy) foam [2]. The initial carbon foams were made by pyrolysis of a thermosetting polymer foam to obtain a carbonaceous skeleton or reticulated vitreous carbon (RVC) foam. A blowing technique or pressure release is utilized to produce foam of the pitch precursor. Then the pitch foam is stabilized by heating in air or oxygen for many hours to cross-link the structure, and 'set' the pitch. In this case, the foam does not melt during the further heat treatment. However, stabilization can be a very time consuming and expensive process depending on the pore size. So ORNL [3] developed a new, little time consuming process to fabricate pitch - based graphitic foams without the traditional blowing and stabilization steps. This new foam is believed to be less expensive and easier to fabricate than the traditional foams.

Klett et al. [1] gave an overall view of the structure of the new graphite foam. The average pore diameter is from 275 to $350 \mu \mathrm{m}$ in the ARA24 - derived foams. The scanning electron micrographs of fracture surfaces, which reveals the pore structure of the ARA24 - derived foams heat - treated at $1000{ }^{\circ} \mathrm{C}$, are shown in Fig. 1 . Inside the foam, there are many spherical pores with small openings. These pores are three - dimensionally interconnected.

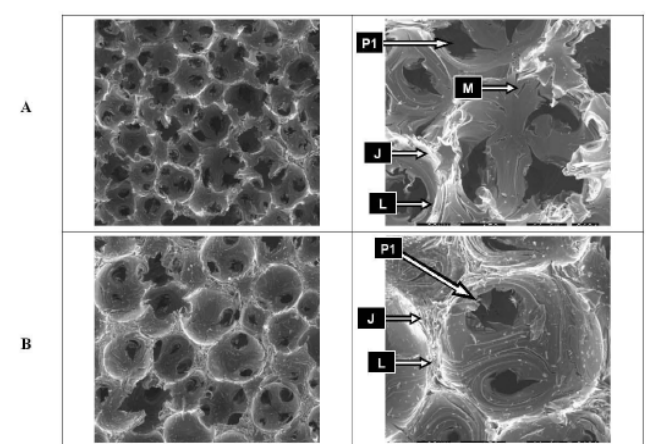

Fig. 1. Photomicrographs of the foams produced from Mitsubishi ARA 24 pitch at different densities A < B (P1: opening pore; M: microcrack; J: junction; L: ligament)[1].

\subsection{Thermal properties of graphite foam}

Because of the special structure of graphite foam, there are several prominent thermal properties in the graphite foam. The graphite foam made by the ORNL process exhibits high effective thermal conductivity (up to $182 \mathrm{~W} /(\mathrm{m} . \mathrm{K})$ ) and low density $\left(0.2-0.6 \mathrm{~g} / \mathrm{cm}^{3}\right)$. The data in Table 1 show that the thermal conductivity in the $\mathrm{z}$ - plane is much larger than the one in the $\mathrm{x}-\mathrm{y}$ plane. It implies that the high thermal conductivity of the graphite foam only exists in a certain direction. This is a disadvantage of the graphite foam. Klett et al. [4] found out that the heat inside the graphite lattice was transferred down the graphite lattice fast, because of the very stiff nature of the covalent bonds (as shown in Fig. 2). Moreover, the position and 
vibration of atoms in the neighboring planes may impede the vibration of atoms in the plane of interest. The crystal perfection controls the thermal performance. In order to achieve high thermal conductivity in the graphite crystal, the structure must be comprised of aligned, straight grapheme planes, and so on.

Table 1. Properties of various graphite foams made by the ORNL method compared to Poco Foam[4].

\begin{tabular}{cccc}
$\begin{array}{c}\text { Graphitiza } \\
\text {-tion rate } \\
\left({ }^{\circ} \mathrm{C} / \mathrm{min}\right)\end{array}$ & $\begin{array}{c}\text { Average } \\
\text { bulk density } \\
\left(\mathrm{g} / \mathrm{cm}^{3}\right)\end{array}$ & $\begin{array}{c}\mathrm{z} \text {-Plane thermal } \\
\text { conductivity } \mathrm{k}_{\mathrm{z}} \\
(\mathrm{W} /(\mathrm{m} . \mathrm{K}))\end{array}$ & $\begin{array}{c}\mathrm{x}-\mathrm{y} \text { Plane } \\
\text { thermal } \\
\text { conductivity k } \\
(\mathrm{W} /(\mathrm{m} . \mathrm{K}))\end{array}$ \\
\hline 10 & 0.45 & 125 & 41 \\
1 & 0.59 & 181 & 60 \\
- & 0.61 & 182 & 65 \\
\hline
\end{tabular}

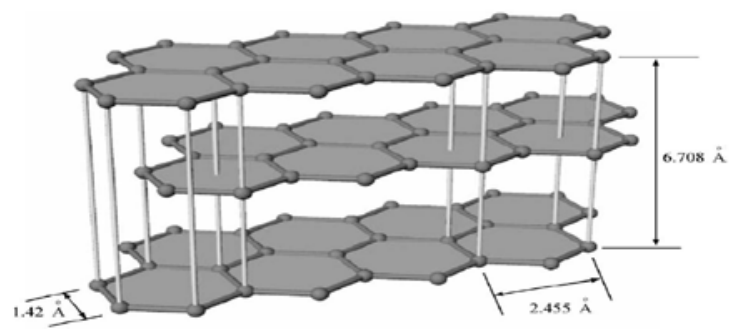

Fig. 2. Planar structure of hexagonal graphite [4].

On the other hand, Yu et al. [5] presented a model which was based on sphere - centered and interconnected unit cubes. The effective thermal conductivity was proved to be a function of the porosity of the graphite foam. Tee et al. [6] used a tapered, anisotropic strut model to predict the overall thermal conductivity of the porous graphite foam. When the size of the foam pores was increased, the convective heat transfer coefficient of the foam was reduced. By using graphite foams as the heat sinks, the enhancement of the convective heat transfer was not only because of its open and inter-connected pores, but also due to its high thermal conductivity and the extremely large surface areas. Furthermore, Straatman et al. [7] validated that the optimal thickness of graphite foam was $3 \mathrm{~mm}$ based on the thermal performance. Meanwhile the heat transfer increase was $28 \%$ at low Reynolds numbers (150000). However, at high Reynolds number, the increase of the heat transfer was only $10 \%$.

\subsection{Pressure drop of graphite foam}

Graphite foam has a very high thermal conductivity, but it also has very high pressure drop, due to the large hydrodynamic loss associated with the open pores in the graphite foam [8]. Leong et al. [9] investigated pressure drop of four different configurations of graphite foams (as shown in Fig. 3). The pressure drops of these four configurations of graphite heat sinks are shown in Fig. 4. For the same inlet flow velocity, the block and baffle foams present the highest and the lowest pressure drop, respectively. On the other hand, Lin et al. [10] approved that the pressure drop through the corrugated passages could be reduced significantly while maintaining a high heat transfer coefficient. As shown in Fig. 5, for forced convection, the air is forced to go through a thin porous wall of graphite foam. Due to the short flow length inside the graphite foam, the pressure drop could be reduced greatly.

\subsection{Advantages and disadvantages}

Based on the special microscopic structures in graphite foams, the advantages of these materials can be summarized: 
(1) High thermal conductivity (thermal conductivity of solid graphite is $1700 \mathrm{~W} /(\mathrm{m} . \mathrm{K})$, and the effective thermal conductivity of graphite foam is more than $150 \mathrm{~W} /(\mathrm{m} . \mathrm{K}))$;

(2) Low density $\left(0.2\right.$ to $\left.0.6 \mathrm{~g} / \mathrm{cm}^{3}\right)$;

(3) High specific surface area (5000 to $50000 \mathrm{~m}^{2} / \mathrm{m}^{3}$ );

On the other hand, there are some disadvantages for the graphite foam materials:

(1) High thermal conductivity only exists in a certain direction;

(2) Due to the small scale pores and complex structures of the foam, the pressure drop through graphite foam is very high.
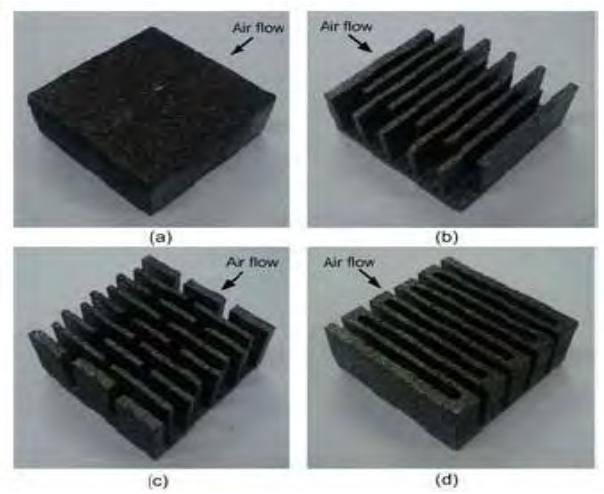

Fig. 3. Tested graphite foam heat sinks of (a) block, (b) staggered, (c) baffle and (d) corrugated configurations [9].

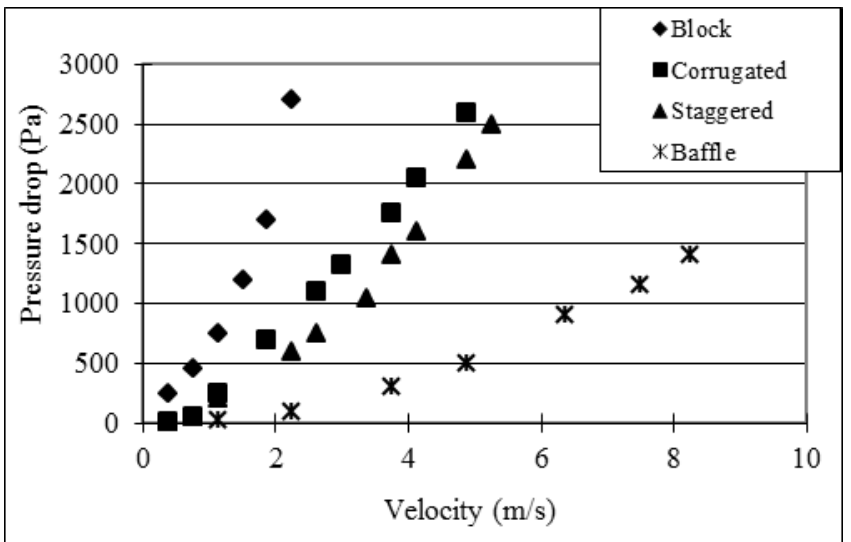

Fig. 4. Pressure drop versus inlet flow velocity of air flow through tested configuration [9].

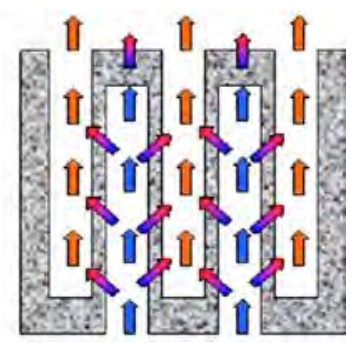

Fig. 5. Flow path inside the corrugated foam [10].

\section{Applications of graphite foams}

Due to the high thermal conductivity, low density and large specific surface area, the graphite foam is a good thermal material for heat exchangers or heat sinks. The major applications of graphite foam as materials for heat exchangers are: electronic package cooling, vehicle cooling systems, energy storage systems, and others. 


\subsection{Electronic package cooling}

Because of the large internal interfaces and the high thermal conductivity, the usage of graphite foam is considered as an effective cooling method to dissipate the high heat flux in electronic equipment. Furthermore, the coolant of electronic equipment can be air instead of water, due to the high thermal conductivity of graphite foam. The removal of water can avoid shorting the circuitry of electronic equipment by water leakage.

Gallego et al. [11] demonstrated that the foam-based heat sink can be used to reduce the volume of the required cooling fluid or eliminate the water cooling system altogether. In terms of thermal performance, the graphite foam is much better than the aluminum. Meanwhile, the graphite foam heat sinks respond to transient loads faster than the traditional aluminum heat sinks. This response time may be crucial for the power electronics. Williams et al. [12] investigated several different channel - insert configurations as mini - heat exchangers by using both copper fins and graphite foams. The graphite foam was proved to have strong potential as a mini - heat exchanger.

On the other hand, the usage of thermosyphons in the thermal management of electronics is established and the methods for evaporator enhancement are of interest. Gandikota et al. [13] investigated the cooling performance of graphite foams for evaporator enhancement in thermosyphons and in pool boiling with FC-72 as the operating fluid. The exhibited thermal resistance was very low, averaging at about $0.024 \mathrm{~K} / \mathrm{W}$ at low heat flux. The thermal resistance rose with increasing heat flux, but still remained very low. Lu et al. [14] used the graphite foam as a wick in a vapor chamber. With ethanol as the coolant, the vapor chamber ( $25 \mathrm{~mm} \times 25 \mathrm{~mm} \times 6 \mathrm{~mm}$ ) had been demonstrated at a heat flux of $80 \mathrm{~W} / \mathrm{cm}^{2}$. The results showed that the performance of a vapor chamber using graphite foam was about twice that of one using a copper wick structure. Furthermore, Coursey et al. [15] found that $149 \mathrm{~W}$ heat load could be dissipated from a $1 \mathrm{~cm}^{2}$ heated base at the operating temperature of $52{ }^{\circ} \mathrm{C}$, by usage of a graphite foam thermosyphon evaporator.

\subsection{Vehicle cooling systems}

Another important utilization of the graphite foam heat exchangers is in vehicle cooling systems. Because of the low density and large specific surface area, it might lead to a light and compact heat exchanger in vehicles. Meanwhile, graphite foam is considered as a potential material to solve critical heat rejection problems that must be solved before fuel cell and advanced power electronics technologies are introduced into automobiles.

The graphite foam could be utilized to produce a light and compact radiator in vehicles. In this case, the radiator might be placed away from the front of vehicles. If the size of the front of vehicles can be reduced, the vehicle does not push so much air in its forward motion. This implies less aerodynamic drag and increase of the fuel efficiency in vehicles. Kett et al. [16] designed a radiator (as shown in Fig. 6) with the carbon foam. Due to the increase of heat transfer coefficients, the number of coolant tubes in the radiator was reduced significantly. A typical automotive radiator with cross section of $48 \mathrm{~cm} \mathrm{x} 69 \mathrm{~cm}$ might be reduced to $20 \mathrm{~cm} \times$ $20 \mathrm{~cm}$ at the same heat removal rate. The reduced size will cut down the overall weight, cost, and volume of the cooling system. Thereby the fuel efficiency can be improved. Moreover, Yu et al. [17] compared a carbon foam fin - tube radiator with a conventional aluminum fin tube radiator. The thermal performance of the carbon foam radiator was increased around $15 \%$ without changing the frontal area or the air flow rate and pressure drop. 


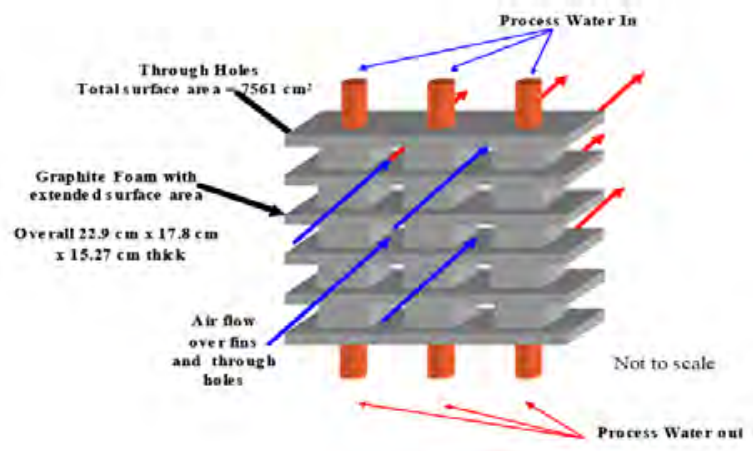

Fig. 6. Configuration of graphite foam radiator [16].

\subsection{Energy storage system}

Because of the high thermal conductivities in the graphite foam, the time used for heat transfer inside the material will be very short. This is a big advantage for energy storage applications. Lafdi et al. [18] investigated the thermal performance of graphite foams infiltrated with phase change materials for space and terrestrial energy storage systems. Because of the high thermal conductivity of graphite foams, the thermal performance of phase change material and foam system was improved significantly. In the phase change material related energy storage process, the higher thermal conductivity leads to a shorter time to charge or discharge, which implies better system performance.

\section{Problems}

Even though the graphite foam is an excellent thermal material, it is still very hard to find graphite foam heat exchangers in the commercial market. Thus, there are some problems blocking the development of graphite foam heat exchangers.

The most important problem facing the graphite foam heat exchanger is the high pressure drop. Because of the complex internal structure of the foam, the flow resistance inside the graphite foam is very high. This causes a high pressure drop through the graphite foam. Due to the high flow resistance, it is difficult for the cooling air to reach all the inter - faces and transfer the heat. Thus, the effective area of heat transfer is reduced greatly, which will result in a low thermal performance. Furthermore, the high pressure drop requires large input of pumping power to push the air through the graphite foam heat exchangers, which will cause a low coefficiency of performance (COP, the ratio of the removed heat to the input pumping power). Garrity et al. [19] proved that the graphite foam heat exchanger had lower COP than the aluminum multilouvered fin. In order to reduce the high pressure drop, it is important to adopt an appropriate configuration of the graphite foams, as discussed in [9-10].

The second problem is that the mechanical properties of the graphite foam are not as good as those of the metal foam. The tensile strength of graphite foam with porosity of $75 \%$ is only $0.69 \mathrm{MPa}$ [20]. However, the tensile strength of nickel foam with the same porosity is 18.44 $\mathrm{MPa}$, which is much higher than the one of graphite foam [21]. In order to reinforce the mechanical properties of graphite foam, it might be useful to introduce some other material to the graphite foam. For instance, the compressive strength can increase ten times after the graphite foam has been mixed with epoxy resin. However, by changing the fabrication process to improve the foam's mechanical properties, the high thermal conductivity might sacrifice [22]. 
The third problem is the dust block. Most research of the graphite foam focus on the electronic equipment heat sinks. Little attention was put to the vehicle radiator applications. The major reason is the dust blocking problem. When the open pores in graphite foams are blocked by dust, the cold air can not reach all inter - faces and bring away the heat. Thus, the effective heat transfer area is reduced greatly and the thermal performance will decrease too. Due to the operating conditions, the dust block problem is more serious in vehicle radiators than in the electronic equipment heat sinks.

Due to these problems, the development of graphite foams is relatively slow and difficult. Much work has to be done before a mature graphite foam heat exchanger appears in the commercial market.

\section{Conclusions and suggestions}

The graphite foam has very high thermal conductivity, low density and large specific surface area. Because of these properties, the graphite foam is considered as a potential thermal material for heat exchangers. The graphite foam can be used as heat sinks to cool electronic packages. Also the graphite foam can be used as a radiator to cool the vehicle engines. Sometimes, the graphite foam can be used in energy storage applications.

However, due to the complex internal structure of the graphite foam, there is a very high pressure drop when the air flows through the graphite foams. There are also some other problems blocking the development of graphite foam, such as the low tensile strength, and the dust block. In order to promote the development of graphite foams as thermal material for heat exchangers, adopting an appropriate configuration might be useful to reduce the pressure drop through the graphite foam. On the other hand, mixing some other material with graphite foam might be helpful to reinforce the mechanical properties of graphite foam. Thus, much work has to be conducted before the graphite foam is accepted as a thermal material of heat exchangers.

\section{Acknowledgments}

The authors acknowledge the financial support from the Swedish Energy Agency and industries.

\section{References}

[1] J. Klett, R. Hardy, E. Romine, C. Walls, and T. Burchell, High-thermal-conductivity, mesophase-pitch-derived carbon foams: effect of precursor on structure and properties, Carbon 38, 2000, pp. 953-973.

[2] W. Ford, Method of making cellular refractory thermal insulating material, 1964, US Patent 3121050.

[3] J. W. Klett, Process for making carbon foam, 2000, US Patent 6033506.

[4] J. W. Klett, A. D. Mcmillan, N. C. Gallego, and C. A. Walls, The role of structure on the thermal properties of graphite foams, Journal of Materials Science 39, 2004, pp. 36593676.

[5] Q. Yu, B. E. Thompson, A. G. Straatman, A unit cube-based model for heat transfer and fluid flow in porous carbon foam, Journal of Heat Transfer 128, 2006, pp. 354-360. 
[6] C. C. Tee, N. Yu, and H. Li, Modeling the overall heat conductive and convective properties of open-cell graphite foam, Modelling Simulation Material Science Engineering 16, 2008, 075006.

[7] A. G. Straatman, N. C. Gallego, B. E. Thompson, H. Hangan, Thermal characterization of porous carbon foam - convection in parallel flow, International Journal of Heat and Mass Transfer 49, 2006, pp. 1991-1998.

[8] A. G. Straatman, N. G. Gallego, Q. Yu, and B. E. Thompson, Characterization of porous carbon foam as a material for compact recuperators, Journal of Engineering for Gas Turbines and Power 129, 2007, pp. 326-330.

[9] K. C. Leong, L. W. Jin, H. Y. Li, and J. C. Chai, Forced convection air cooling in porous graphite foam for thermal management application, 11th Intersociety Conference on Thermal and Thermomechanical Phenomena in Electronic Systems, 2008, pp. 57-64.

[10] Y. R. Lin, J. H. Du, W. Wu, L. C. Chow, W. Notardonato, Experimental study on heat transfer and pressure drop of recuperative heat exchangers using carbon foam, Journal of Heat Transfer 132, 2010, 091902-1.

[11] N. C. Gallego, and J. W. Klett, Carbon foams for thermal management, Carbon 41, 2003, pp. 1461-1466.

[12]Z. A. Williams, and J. A. Roux, Graphite foam thermal management of a high packing density array of power amplifiers, Journal of Electronic Packaging 128, 2006, pp. 456465.

[13] V. Gandikota, and A. S. Fleischer, Experimental investigation of the thermal performance of graphite foam for evaporator enhancement in both boiling and an FC-72 thermosyphon, Heat Transfer Engineering 30(8), 2009, pp. 643-648.

[14] M. H. Lu, L. Mok, and R. J. Bezama, A graphite foams based vapor chamber for chip heat spreading, Journal of Electronic Packaging 128, 2006, pp. 427-431.

[15] J. S. Coursey, J. Kim, and P. J. Boudreaux, Performance of graphite foam evaporator for use in thermal management, Journal of Electronic Packaging 127, 2005, pp. 127-134.

[16]J. Klett, R. Ott, and A. McMillan, Heat exchangers for heavy vehicles utilizing high thermal conductivity graphite foams, SAE Technical Paper 2000-01-2207, 2000.

[17]Q. Yu, A. G. Straatman, B. E. Thompson, Carbon - foam finned tubes in air - water heat exchangers, Applied Thermal Engineering 26, 2006, pp. 131-143.

[18]K. Lafdi, O. Mesalhy, and A. Elgafy, Graphite foams infiltrated with phase change materials as alternative materials for space and terrestrial thermal energy storage applications, Carbon 46, 2008, pp. 15-168.

[19]P. T. Garrity, J. F. Klausner, R. Mei, Performance of aluminum and carbon foams for air side heat transfer augmentation, Journal of Heat Transfer 132, 2010, 121901-1.

[20]M. D. Haskell, Thermal resistance comparison of graphite foam, aluminum, and copper heat sinks, http://www.electronics-cooling.com/2006/02/thermal-resistance-comparisonof-graphite-foam-aluminum-and-copper-heat-sinks/.

[21]S. B. Zhao, Thought about the exponential item in formulas calculating tensile strength for high - porosity materials, Materials and Design 23, 2002, pp. 497-499.

[22] ORNL's graphite foam may aid transportation, http://www.ornl.gov/info/ornlreview/v33_3_00/foam.htm. 